\title{
Gender and Field of Study as Determinants of Perceptions Regarding Employment Prospects Among Final Year Students: Case of a University of Technology in South Africa
}

\author{
Prof. Crispen Chipunza \\ Department of Business Management, Human Resource Management Unit \\ Central University of Technology, Free State, South Africa \\ Email: cchipunza@cut.ac.za
}

\section{Doi:10.5901/mjss.2014.v5n20p3017}

\begin{abstract}
Since the introduction of the affirmative action policy in South Africa to promote employment among the previously disadvantaged groups in society, there is dearth of empirical data on its effects on perceptions of employment after graduation among male and female students from one race group, studying at other types of institutions called Universities of Technology (UoTs). The objective of the study was to investigate the extent to which gender and field of study differences exist among black male and female final year students' perceptions regarding their employment prospects. The sample consisted of 103 black male and 95 black female students from a UoT, who were about to complete their Bachelor of Technology (B. Tech) degrees in Accounting $(n=56)$, Human Resource Management (HR) $(n=82)$ and Information and Communication Technology (ICT) $(n=60)$. A self-report questionnaire was used to collect data. The results showed some differences in gender and field of study regarding determinants of employment perceptions, perceptions regarding the importance of different job-seeking behaviours, as well as perceptions regarding prospects of employment upon completion of studies. The study concludes that black male and female students' perceptions of employment as beneficiaries of the South African government's affirmative action employment policies need to be understood in the context of their job seeking behaviours.
\end{abstract}

Keywords: race; gender; field of study; affirmative action; employment prospects

\section{Introduction}

The Affirmative Action policy was introduced in South Africa eighteen years ago. The purpose of the policy was to promote gender and racial equality in the workplace by providing equal opportunities to those who were previously disadvantaged during the apartheid regime (Madi, 1997). The creation of employment opportunities was therefore at the centre of the affirmative action policy. However, the policy has direct effects, either negative or positive on particular individuals who are either beneficiaries or non-beneficiaries of the policies. Furthermore, the policy raises a lot of questions related to perceptions of one's employment prospects, for different individuals from the different racial and gender groups in South Africa. In addition, discussions on affirmative action policy in South Africa have centred on its economic benefits among different gender and racial groups. Individual effects of the policy are seldom studied.

Within the South African context, there is no doubt that affirmative action policy itself creates questions of whether one will be employed or not among individuals from different racial gender groups. For example, white males can ask themselves whether they stand a chance of being employed even if they qualify for the position. Black women can also ask themselves whether they will be employed because they are the best candidate or because they are black women. Such questioning creates self- perceptions and can determine the actions one can take to look for employment. The effects of affirmative action are detrimental in situations where one has devoted much time, money and effort, like studying for a particular degree at a university, and only finding out that at the end, due to certain policies, the chances of employment are limited. Numerous studies (e.g., Singer, Stacey and Ritchie, 1987) pertaining to perceptions of employment prospects among students as a result of government policy were conducted, but mostly in the Western world. Few studies ( e. g., Tomu, 2013) in South Africa have been conducted at 'traditional universities' using students from Psychology, Sociology and Pharmacy. In addition, known South African studies compared two or more race groups, and field of study. No study has used gender and field of study of a single race group to investigate the effects of affirmative action policies in South Africa on final year students' perceptions of their employment prospects at a University of Technology (UoT). 


\section{UoTs in South Africa}

The transformation that took place within the higher education sector between 2001 and 2004 resulted in issues of equity and access in/to education and educational resources being leveraged across all race groups, through mergers and incorporations of the then existing 36 institutions into 23 higher education learning institutions. Peculiar to the transformation was the establishment of Universities of Technology (UoTs) who, previously as Teknikons, had limited access by other race groups other than whites. The establishment of UoTs widened access to higher education for the previously excluded groups (ie. blacks, coloured and Indians) (CHE, 2001). One characteristic of UoTs, which differentiates them from other universities, is that they are more responsive to the employers' demands due to their vocationally-oriented approach which makes them work more with industry. The resultant are competent, hands-on professional graduates who are relevant to the needs of society (CHE, 2006). There is evidence that UoTs' graduates are preferred by industry and commerce and therefore easily observed in the labour market ().

This study explored perceptions of employment prospects among black make and female final year students registered for three different degree programmes at a University of Technology (UNT) in South Africa. It sought to determine whether perceptions of employment prospects varied among males and females, as well as across different fields of study. Lastly, the study sought to determine whether perceptual differences exist between black male and female students' attributions of employment prospects in terms of external factors such as government policies or internal factors such as one's skills and abilities.

\section{Justification for the Study}

With the high poverty and unemployment levels facing South Africa, it is imperative to investigate black male and female students' perceptions regarding their employment prospects, the extent and type of the effects of South Africa's employment policies on them as beneficiaries in their final year of study. The information gleaned from such a study will explain some job-seeking activities black female and male students will perceive to be important when seeking employment. For example, it is likely that those who perceive barriers to employment prospects due to external factors such as government policies might perform well during interviews and are more likely to use proactive job seeking strategies.

Today the rate of unemployment in South Africa among youth with diplomas and degree holders (Pauw, Oosthuizen, \& Van der Westhuizen, 2008) is reported to have risen from $6.6 \%$ in 1997 to $9.7 \%$ in 2010, especially among blacks who find themselves enrolled in low employment prospects fields, such as the social sciences, compared to whites. With such scenarios, disillusionment among the black educated is likely to be created, many of whom have struggled to raise money to get the qualifications and therefore go into the labour market with the expectations of getting employed. Because affirmative action policy was meant to deal with high unemployment rates among previously disadvantaged groups (black female and male included) its presence is likely to create perceptions of easy employment among them than other race groups and also cause attributions of possible employment to be viewed as external or internal. Thus, if one views prospects of unemployment as externally determined, such as government policy, they are likely to feel hopeless since they assume that nothing can be done about it. On the other hand, if that attribution is internally viewed, such as lack of skills or ability, which can be determined by the type of qualification, one is likely to change the course of study to increase better chances of employment. It is therefore important to investigate the impact that affirmative action has had on black students as the benefiting group of the affirmative action employment policies (Lawless, 2006).

In South Africa, the demands for students, most of whom are blacks, with social sciences in the labour market is low, yet enrolments in these fields are high (Koen, 2003). Graduates in the medical sciences, accounting, Information and Communication Technology (ICT), agriculture, , whether black or white, for example, are employed faster than those in more general degrees (Moleke, 2005). Skills mismatch is one of the factors bedevilling graduate unemployment in the country and therefore responsiveness in the labour market could be improved with results of the study. According to the government document, Accelerated and Shared Growth Initiative for South Africa (Asgisa)(2006), scarce skills shortage in areas such as natural sciences, ICT, management sciences, health and medical sciences is caused by the great number of black graduates in social sciences where chances of getting employed are limited. With such evidence, questions on how black students decide on what to study and whether they receive any guidance in making career decisions arise. For example, do the students' decisions on what to study contribute to the concern or lack of it pertaining to employment prospects? This is important, since in South Africa, having a degree is not a panacea to employment, but 
the type of degree is a critical factor in determining possession of necessary skills for employment in that field. Furthermore, knowledge of students' perceptions of employments prospects can be good starting point to design policies that will help those who think are excluded from employment policies become economically independent.

\section{Literature Review}

Since the introduction of Affirmative Action as a policy that attempts to promote employment equality based on gender and race (Grobler, Warnich, Carrell, Elbert \& Hatfield, 2011), it has been viewed by others as a beacon of hope and by others as a threat to their personal security (Mandela, 1991). Even though one of its focus is to overcome barriers to equal employment opprtunities, different connotations by different people entail that the concept is defined differently by different people. For others, it means preferential treatment of other racial and gender groups; for others it might mean preferential redistribution of resources for particular a gender, while for others it might denote preferential assistance with finance for institutions and business in previously disadvantaged communities (Hunter, 2012). Within the context of South Africa, connotations that are emotionally charged in relation to the concept are often heard as 'apartheid in reverse' or 'reverse discrimination' (Gobrler, et al. 2011). The different definitions are an indication of different attitudes towards the policy. These attitudes are likely to lead to different perceptions of self and behaviors in schools, tertiary institutions and work environments. In this study, affirmative action is regarded as referring to policies that take gender, race or ethnicity into account in an attempt to promote equal opportunity in a diverse society like South Africa in redressing disadvantages brought about by overt, institutional or involuntary discrimination.

Controversial issues around the concept in South Africa are that sometimes people who are not qualified, especially among blacks, are selected because of the policy, leading non-beneficiaries of affirmative action to assume that they will never get employment even if they have the required qualifications. In addition the problem regarding affirmative action lies in the use of qualifications in employee selection (Edigheji, 2007). Some critics advocate for complete 'preferential' selection approach, while others advocate for 'pure qualifications' approach (Nel, 2011). Despite these varied arguments, it is not surprising to note that other factors such as networking and nepotism can play an important role in any selection of employees regardless of whether one is a beneficiary or non-beneficiary of the policy.

\subsection{Skills Shortages}

In many countries, mismatches between fields of study and demand for graduates of certain caliber are common (ASGISA, 2006). In South Africa, the oversupply or undersupply of black graduates is an issue the current government is battling with. For example, the observation of oversupply of black graduates is often combined with lack of competences (Ranuwihardjo, 1995) leading the graduates ending up taking jobs where they do not utilise the learned skills and therefore not contributing to socio-economic development of the country. Thus, there is mismatch between competencies of black graduates and the needs of the employment system. Generally though, studies on graduate unemployment are limited in literature, with many of unemployed graduates reported in both developed and developing countries (Schomburg, Ulrich Teichler, 2006; Oosthuizen \& C. Van der westhuizen, 2008). The common concern in South Africa for example is the view of unemployment conditions of black graduates from institutions of higher learning when considerable large financial investments have been made in these institutions hoping for return $\mathrm{s}$ on investments (Altbeker \& Storme, 2013).

\subsection{Perceptions regarding employment}

In South Africa, evidence of research at a University of Technology (UoT) to determine perceptions of black male and female final year students pertaining to employment prospects as they reach the end of their preparation for entering the labour market is limited. Available literature elsewhere (Singer et al., 1987) compares attributions of the unemployed/unemployment, without taking into account variables such as race, gender, and type of programme enrolled for, while other studies (Winefiled, Wunefiled, Tiggermann \& Goldney, 1991) emphasise the psychological effects of not being employed. In Britain, Furnham (1982a , 1982b) compared causal attributions concerning unemployment made by employed and unemployed, while Gurney(1908) found that perceptions of self were affected when school leavers did not get employment. Within South Africa, research close to attributions of unemployment was the one done Moleke (2005) on graduates' experiences on finding work. Most South African literature is on statistics regarding unemployed graduates (Burger \& Woolard, 2005; Bhorat \& Oosthuizen, 2005). Such information is needed mostly by government for planning 
purposes.

Studies that compared attributions to external or internal factors (Gurney, 1981) found that unemployed males were more likely to attribute both getting and not getting work significantly to external factors than did the employed males, but there were no differences between the female groups. In another study a comparison of before and after school on attributions of causes for unemployment shifted for internal to external, respectively. There were no causal links to explain the shifts. Research on gender, race and type of programme by Furnham (1984) among school leavers showed that parent's employment status accounted for perceptions of unemployment. The study further found significant class differences in the respondents' beliefs about sex and racial advantage in prospects of getting a job. Furthermore, males as opposed to females had a high propensity of believing that external factors such as government policy and sheer luck were critical factors to being employee. Further comparisons between working class and middle class participants showed that the working class tended to stress external and educational factors whereas middle class tended to stress internal and effort factors. However, in this study, participants were school leavers and not final year university of technology students as is the case in the current study.

\section{Theoretical Framework}

The study is based on attribution theory (Heider, 1958; Jones \& Davis, 1965; Kelly, 1967; Jones \& Nesbert, 1972). The basic tenet of the theory is that people have innate need to understand and control their immediate environments; hence, individuals develop causal explanations for significant events as they experience them. These beliefs about causality influence expectations, which in turn influence subsequent behaviour (Barone, Bayne \& Branscombe, 2006). Attribution theorists are therefore concerned about perceived causes and not actual causes of events and the consequences of those perceptions (Fosterling, 2001). In relation to the current study, this entails that black male or female students who attribute low employment prospects to affirmative action policies are less likely to perform well during interviews, while someone who attributes low employment prospects to an inappropriate field of study (field of study that does not belong to scarce category ) may change his or her study area to guarantee themselves better employment prospects. In simple terms, the theory states that people explain an action by either attributing it to something to do with the person who performs it such as ability or skill (i.e. an internal attribution) or by attributing it to some external source such a affirmative action policy (i.e. an external attribution). In tandem with the current study, a black male or female student may attribute their negative or positive perceptions of prospective employment to their ability, skill, effort or chance/luck, while negative or positive perceptions might attributed to government policies.

Based on the above, the specific research questions were as follows:

1. As beneficiaries of employment policies, do black male and female final year students have positive perceptions regarding employment prospects?

2. Is there a significant difference in perceptions of employment prospects among final year black male and female students studying for degrees in Information and Communication Technology, Accounting, and Human Resources Management (HR)?

3. Are final year students who are classified beneficiaries of affirmative action policies in South Africa (black males and females) attribute perceptions of employment prospects to internal factors (such as abilities and skills) or external factors, such as employment policies and luck?

\section{Hypotheses}

1. As beneficiaries of employment policies, female final year students are more confident than male final year students about their employment prospects.

2. As beneficiaries of employment policies, black final year female students are significantly more confident than male final year students that their degree will ensure employment

3. As beneficiaries of employment, black final year female students are less likely to experience feelings of hopelessness than black female final year students.

4. Black female final year students who are classified as beneficiaries of employment policies in South Africa are more likely to attribute negative employment prospects to internal factors, such as one's skills and abilities, than male beneficiaries of employment policies.

5. Final year students in ICT and Accounting are more likely to report positive perceptions about their employment prospects than final year Human Resource Management students. 


\section{Methodology}

The study was done within the positivist paradigm (Welman, Kruger and Mitchell, 2005:6) which underlies the natural scientific method in human behavioural research and holds that research must be limited to what can be observed and measured objectively. The design was a cross sectional one, and the approach was purely quantitative. The independent variables in the study were gender (male versus female) and field of study (ICT, Accounting and Human Resources Management). The dependent variable consisted of measures relating to students' perceptions regarding employment prospects.

\subsection{Data collection}

A self-report Likert type scale questionnaire was used to collect data. The questionnaire was adapted from one developed by Dayton (1981) and Gurney (1981) and some items were changed to suit the South African context and research questions. Demographic variables on gender and field of study were in the first section of the questionnaire, including some questions of study sponsorships. Section two had questions relating to 'attribution' which solicited the extent to which final year students believe that unemployment individuals with degrees is mainly a function of ( or internal factor (personal attributes ) or external factors(nature of jobs available, government policies, race or gender). Examples are: Unemployment is high because the jobs are simply not there'. The third had questions relating to job seeking activities that the students perceived to be important when seeking employment. Examples are: Writing up and sending your CV; Seeking help from groups that belong to you. The last section had question designed by the researcher measure the level of among the students regarding possibilities of being unemployed. Example: Thinking about the prospects of employment can be very stressful at times. Content validity was assessed by comparing questionnaire items with the literature review (de Vos, et al 2002) and using experts in the area study. Reliability was calculated by obtaining a Cronbach Alpha coefficient

\subsection{Sample and sampling procedure}

The sample consisted of 198 black male and female students from three degree programmes in the two faculties. Of the 198, 52.02\% $(n=103)$ were males and $47.98 \%(n=95)$ females. Approximately $30.3 \%(n=60)$ of the students were from Engineering Faculty, studying for ICT, 28.28\% ( $n=56)$ were studying Accounting and $41.41 \%(n=82)$ were studying HR. Accounting and HR students belonged to the Management Sciences Faculty. ICT had a smaller sample than Accounting and HR.

Table 1 below shows the gender percentages and numbers of the total sample within the different fields of study.

Table 1: Gender totals within the different fields of study

\begin{tabular}{|c|c|c|c|}
\hline Degree & Female & Male & Total \\
\hline Accounting & $13.64 \%(n=27)$ & $14.65 \%(n=29)$ & 56 \\
\hline ICT & $11.11 \%(n=22)$ & $19.19 \%(n=38)$ & 60 \\
\hline HR & $23.23 \%(n=46)$ & $18.18 \%(n=36)$ & 82 \\
\hline Total & $47.98 \%(n=95)$ & $52.02 \%(n=103)$ & 198 \\
\hline
\end{tabular}

High female enrollment is HR and males in ICT indicate the large high enrollment proportions of female students in the management sciences as well as males in natural sciences in South African universities. The age range of participants was between 19 and 32, with the majority between the ages of 20 and 27. The sampling used was convenient/purposive. Collection of data was done at the end of each lecture session after the researcher had sought permission from lecturers in advance.

\subsection{Data Analysis}

Basic descriptive statistics were used to analyse the data to determine whether or not to proceed with further analyses without transformation as well as to check the extent to which the data satisfied the requirements for parametric data analysis. Standard procedures were used to clean data. Reliability analyses were performed on each sub-scale to test 
the data's internal consistency. Where appropriate, the scores were reverse-scored prior to running reliability analyses. In cases where the reliability indices showed an acceptable level of internal consistency, composite scores were derived which provided a single score that indicated each participants' relative standing on the dimension being assessed. These composite scores served as dependent variables for testing the specific hypotheses investigated in the study. The hypotheses were tested by running a series of Analyses of Variance (ANOVA) in which gender and field of study served as independent variables. In cases where significant main effects and/or interactions were found, appropriate multiple comparison tests were applied (e.g. Tukey's test).

\section{Results}

It will be recalled that the purpose of the study was to investigate male and female final year university of technology students' perceptions regarding their employment prospects. In particular, the study sought to examine the extent to which perceptions regarding employment prospects would differ across gender and field of study.

In terms of research participants, $85 \%$ of females and $77 \%$ of males had all their fees paid by NSFAS. Three percent of females had bursaries compared to and $5 \%$ makes. The rest of the groups had fees paid by their parents. With regards to career plans, $61 \%$ of females compared to $48.7 \%$ of male participants had intentions of studying further. About $2 \%$ of the female participants had intentions of starting a business compared to approximately $4 \%$ of the male students. Forty one of the male participants and $24.3 \%$ of the female participants indicated that they were planning to seek employment at the end of Bachelor of Technology degree. Almost $4 \%$ of the male participants had intentions of studying None of the male participants were unsure of their career plans while $1.4 \%$ of the female participants indicated that they were not sure of their career plans after obtaining their degree.

\section{Findings}

Results of perceptions regarding determinants of employment prospects are presented below. In all sections, the mean scores range from $1-4$, with high scores indicating greater degree of agreement with the statement or construct.

\subsection{Perceptions Regarding Determinants of Employment Prospects.}

Table 2 shows the mean scores with respect to participants' perceptions of the role of luck, qualifications, government policies and individual responsibility in determining employment prospects by race, gender and field of study. Standard deviations are shown in parentheses.

Table 2: Mean scores with respect to perceptions regarding determinants of employment prospects

\begin{tabular}{|c|c|c|c|c|}
\hline & Luck & Qualifications & Government Policies & Individual Responsibility \\
\hline $\begin{array}{l}\frac{\text { Gender }}{\text { Male }} \\
\text { Female }\end{array}$ & $2.44(0.52) 2.27(0.45)$ & $3.22(0.44) 3.07(0.44)$ & $2.54(0.72) 2.59(0.55)$ & $2.33(0.53) 2.34(0.49)$ \\
\hline $\begin{array}{l}\frac{\text { Field of }}{\text { Study }} \\
\text { Accounting } \\
\text { ICT } \\
\text { HR }\end{array}$ & $\begin{array}{c}2.17(0.49) 2.17(0.38) 2.44 \\
(0.50)\end{array}$ & $\begin{array}{c}3.16(0.42) 3.17(0.48) 3.09 \\
(0.46)\end{array}$ & $\begin{array}{c}2.60(0.65) 2.77(0.59) 2.32 \\
(0.55)\end{array}$ & $\begin{array}{c}2.63(0.47) 2.79(0.51) \\
2.49(0.53)\end{array}$ \\
\hline
\end{tabular}

With respect to luck, a marginally significant main effect of gender was found $(F(1,174)=3.24, p<.07)$. Table 1 shows that the mean for males was slightly higher than that for females, suggesting that, overall, males endorsed statements referring to luck more strongly than females. There was a highly significant main effect of field of study $F(2,174)=5.93$, $p<.003$. Figure 1 shows this main effect. 


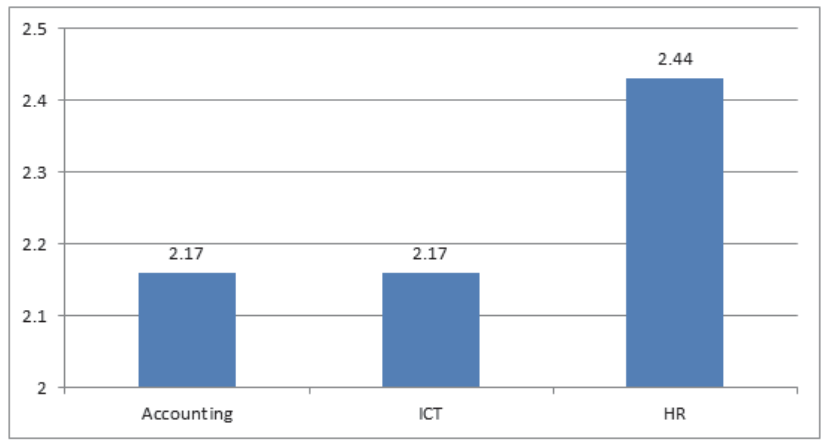

Figure 1: Mean scores for the perceived role of luck across participants from the three different fields of study

Figure 1 shows that the mean for HR students was significantly higher than that for Accounting and ICT students. HR students viewed luck as playing a significant role in determining one's chances of post-qualification employment more strongly than accounting and ICT students. None of the interactions were statistically significant (pa// >0.05).

With respect to the perceived role of qualifications in determining employment prospects, the analysis showed a significant main effect of gender $(F(1,215)=4.41, p<0.03)$. Males perceived qualifications to be a determining factor in improving one's chances of being employed more strongly than females. The main effect of field of study was not significant $(F(2,215)=0.39, p>0.05)$. Furthermore, none of the interactions were statistically significant (pall $>0.05)$.

With regards to the role of government policies in determining employment prospects, the main effect of gender was not statistically significant $(F(1,180)=0.23, p>0.05)$. There was also a statistically significant main effect of field of study $(F(2,180)=8.03, p<0.0001)$. Figure 2 shows the mean scores for the perceived role of government policies across participants from the three different fields of study.

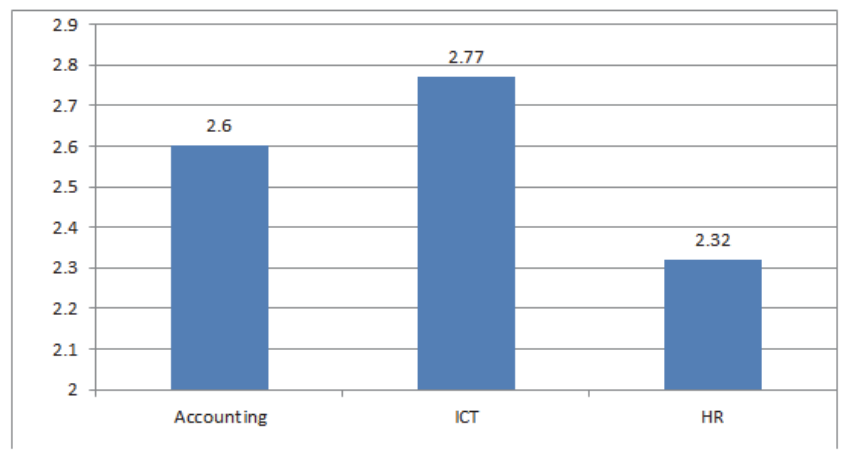

Figure 2: Mean scores for the perceived role of government policies across participants from the three different fields of study

Regarding the role of government policies, Tukeys's multiple comparison tests showed that the mean for ICT students was significantly higher than those of both Accounting and HR students. Therefore, it appears that ICT students perceive government policies to play a more significant role in determining one's chances of employment than Accounting and HR students. None of the interactions were statistically significant (pall >0.05).

Analysis of the data with respect to perceptions regarding the role of individual responsibility in determining employment prospects showed no significant main effect of gender $(F(1,19) 1=0.07, p>0.05)$. However, the main effect of field of study was significant $(F(2,191)=3.96, p<0.02)$. Figure 3 shows this main effect. 


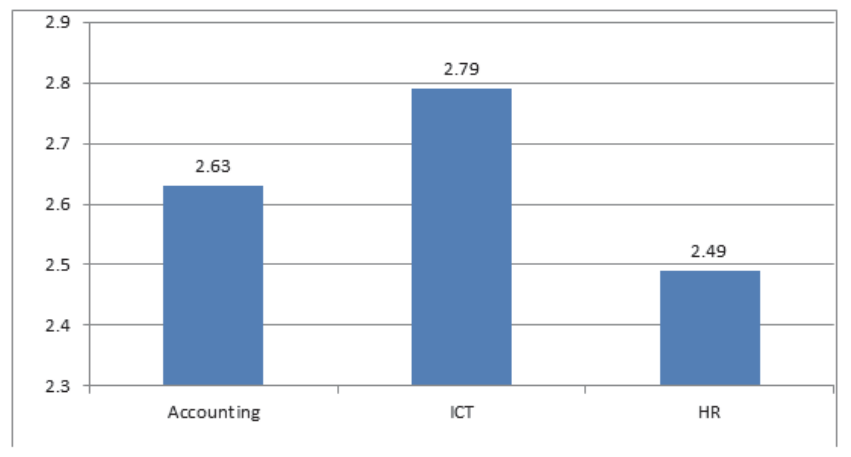

Figure 3: Mean scores for the role of individual responsibility in determining employment prospects from the three different fields of study

Multiple comparison tests indicated that the mean for HR students was significantly lower than the means for both Accounting and ICT students. These findings suggest that, overall, HR students did not agree with statements which propose that individual responsibility plays a major role in determining employment prospects. There was also a statistically significant interaction between gender and field of study $(F(2,191)=6.60, p<0.002)$. Figure 4 shows this interaction.

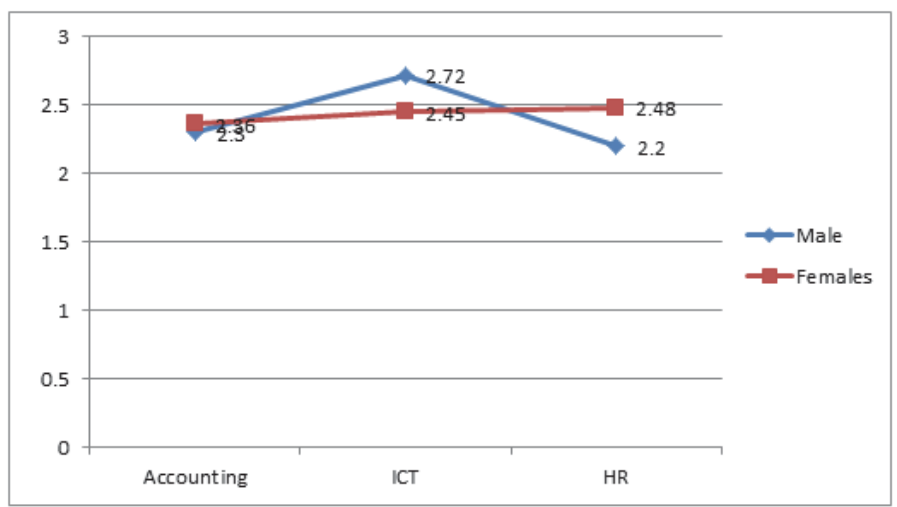

Figure 4: Mean scores for an interaction between gender and field of study for the role of individual responsibility in determining employment prospects

Multiple comparison tests showed that there were no significant mean differences between the male and female students in the Accounting field. However, there were significant mean differences between male and female students in both the ICT and HR fields of study. Among ICT students, males endorsed the role of individual responsibility in determining employment more strongly than females. Within the HR field of study, however, the opposite was found: female students endorsed the role of individual responsibility in determining employment prospects more strongly than male students.

\subsection{Perceptions Regarding the Importance of Different Job-Seeking Behaviors}

With respect to perceptions regarding the importance of various job seeking behaviours in determining employment prospects there were statistically significant main effects and interactions for the following job seeking behaviours: searching the career sections of newspapers, taking a job interest test, sending out e-mails of enquiry, approaching lecturers for job related assistance as well as doing volunteer work related to one's field of study. Table 2 shows the mean scores for these variables. Standard deviations are in parentheses. 
Table 3: Mean scores with respect to perceptions regarding the importance of different job seeking behaviors.

\begin{tabular}{|c|c|c|c|c|c|}
\hline & $\begin{array}{c}\text { Searching career sections } \\
\text { of newspapers }\end{array}$ & $\begin{array}{c}\text { Taking a job } \\
\text { interest test }\end{array}$ & $\begin{array}{c}\text { Sending out e-mails } \\
\text { of enquiry }\end{array}$ & $\begin{array}{c}\text { Approaching lecturers for job } \\
\text { related assistance }\end{array}$ & $\begin{array}{c}\text { Doing } \\
\text { volunteer work }\end{array}$ \\
\hline$\frac{\text { Gender }}{\text { Male }}$ & $3.42(1.00)$ & $2.61(1.12)$ & $3.35(0.98)$ & $3.04(1.10)$ & $3.59(1.13)$ \\
Female & $3.54(0.97)$ & $2.79(1.13)$ & $3.48(1.01)$ & $3.13(1.17)$ & $3.58(1.08)$ \\
\hline$\frac{\text { Field of }}{\text { Study }}$ & $3.48(0.88)$ & $2.74(1.10)$ & $3.19(0.94)$ & $2.68(1.10)$ & $3.29(1.09)$ \\
Accounting & $3.45(1.10)$ & $2.47(1.32)$ & $3.78(0.87)$ & $3.38(1.06)$ & $3.40(1.18)$ \\
ICT. & $3.50(1.05)$ & $2.89(1.10)$ & $3.28(1.07)$ & $3.19(1.15)$ & $4.07(0.91)$ \\
HR & & & & & \\
\hline
\end{tabular}

As shown in Table 3, the mean for female students was higher than that of male students (3.54 vs 3.42). Female students were therefore more positive than male students about the importance of searching the career sections of newspapers when one is seeking employment. With regards to perceptions on the importance of taking a job interest test, the data showed a statistically significant main effect of gender $(F(1,235)=8.37, p<0.004)$. The mean for female students was higher than that of male students (2.79 vs 2.61). Female students were therefore more positive than male students about the importance of taking a job-interest test when seeking employment.

With regards to sending out e-mails of enquiry when seeking employment, the analysis showed a statistically significant main effect for field of study $(F(2,235)=5.89, p<0.003)$. Figure 5 shows this main effect.

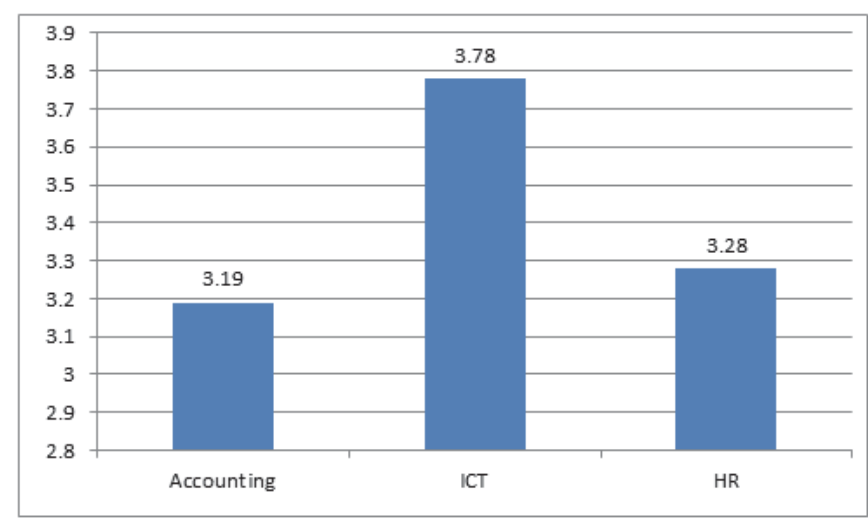

Figure 5: Mean scores for perceptions regarding the importance of sending out e-mails of enquiry when seeking employment across participants from the three different fields of study

Multiple comparison tests showed that the mean for ICT students was significantly higher than that of HR and Accounting students. This suggests that ICT students were more likely to endorse the sending out of e-mails of enquiry than HR and Accounting students.

With regards to the importance of approaching lecturers for job related assistance, the analysis showed a statistically significant main effect of field of study $(F(2,235)=8.47, p<0.0001)$. Figure 6 shows this main effect. 


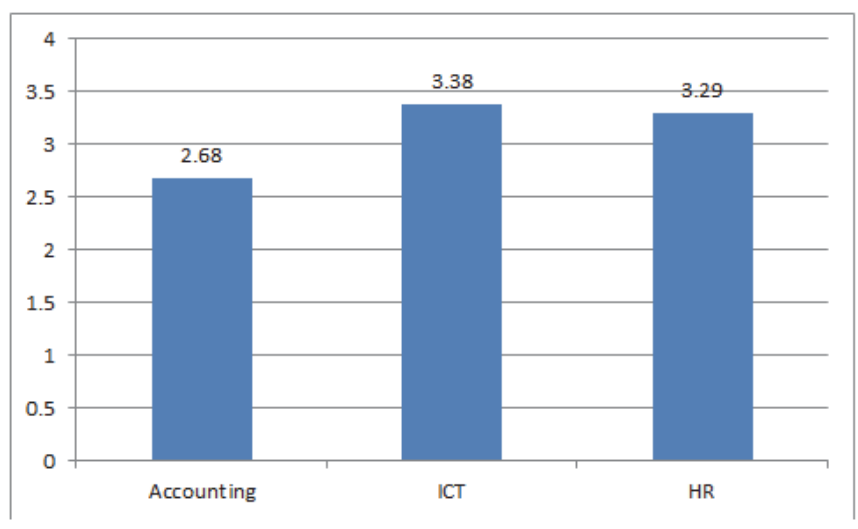

Figure 6: Mean scores for perceptions regarding the importance of approaching lecturers for job related assistance when seeking employment across participants from the three different fields of study

The analysis showed that Accounting students compared to the ICT and HR students were significantly less likely to perceive approaching lecturers for job related assistance.

Further showed a statistically significant interaction between gender and degree $(F(2,235)=4.00, p<0,02)$. Figure 7 shows the interaction between gender and field of study.

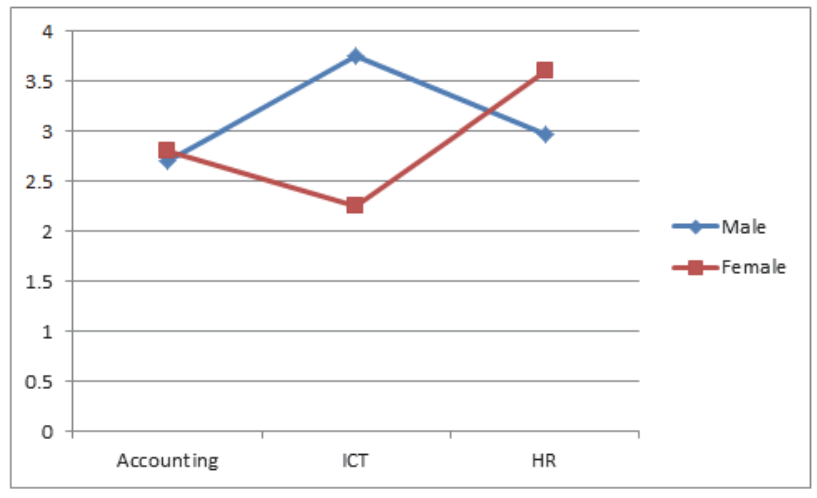

Figure 7: Mean scores for the interaction of field of study and gender for perceptions regarding the importance of approaching lecturers for job related assistance when seeking employment

The analysis showed no significant difference between male and female students in the field of Accounting with respect to perceptions regarding the importance of approaching lecturers for job related assistance. There was, however, a statistically significant difference between male and female students within the ICT and HR fields of study. Among the ICT students, the data indicated that males compared to females endorsed the importance of approaching lecturers for job related assistance much more strongly. Among the HR students, however, the opposite was true with more female students being more likely to perceive approaching lecturers for job related assistance as being very important when seeking employment.

With regards to perceptions about the importance of doing volunteer work, the analysis showed a statistically significant main effect of field of study $(F(2,235)=12.45, p<0.0001)$. Figure 8 shows this main effect. 


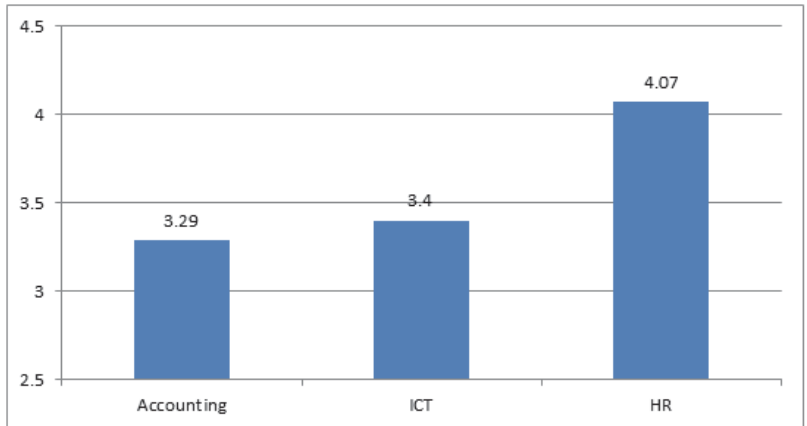

Figure 8: Mean scores across participants from the three different fields of study for perceptions regarding the importance of doing volunteer work related to ones' field of study when seeking employment

HR students strongly endorsed the idea of doing volunteer work related to one's field of study when seeking employment, while Accounting students were least likely to perceive volunteer work as being important when seeking employment.

\subsection{Perceptions Regarding Individual Prospects of Employment upon Completion of Current Degree Program}

Table 4 shows the mean scores (standard deviations in parentheses) with respect to participants' perceptions regarding their own prospects of employment upon completion of their degree. This relates specifically to: (1)Confidence in their own degree ensuring employment, and (2) Individual judgments regarding their own levels of hopelessness when considering employment prospects.

Table 4: Mean scores of participants' perceptions regarding their own prospects of employment

\begin{tabular}{|c|c|c|}
\hline & Lack of Confidence in own degree & Hopelessness \\
\hline $\begin{array}{c}\text { Gender } \\
\text { Male Female }\end{array}$ & $2.18(0.56) 2.23(0.64)$ & $2.47(0.81) 2.52(0.62)$ \\
\hline $\begin{array}{c}\text { Field of Study } \\
\text { Accounting } \\
\text { ICT }\end{array}$ & $1.97(0.45)$ & $2.72(0.70)$ \\
HR & $1.98(0.41) 2.67(0.57)$ & $2.81(0.73) 1.95(0.69)$ \\
\hline
\end{tabular}

The items relating to confidence levels were worded in such a way that the researcher could investigate the extent to which participants experienced a lack of confidence in their degree ensuring employment. Thus, the higher the score, the greater the lack of confidence in participants' degrees ensuring employment. With respect to lack of confidence in one's own degree, there was no main effect of gender $(F(1,189)=0.36, p>0.05)$. However, was a significant main effect of field of study $(F(2,189)=39.80, p<0.0001)$. Figure 9 shows this main effect.

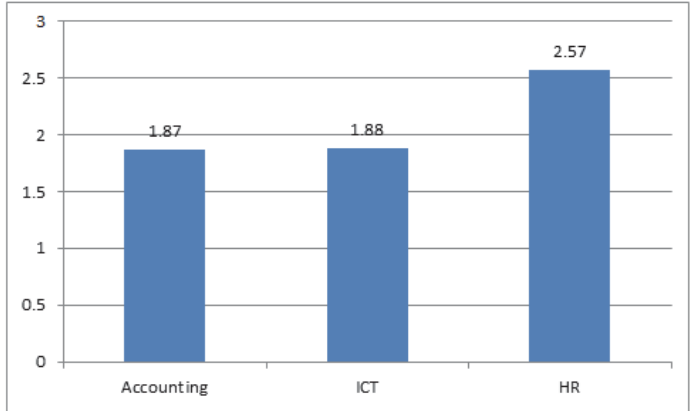

Figure 9: Mean scores indicating student's lack of confidence in their own degree ensuring employment from the three fields of study. 
The multiple comparison tests showed that the mean for HR students was significantly higher than the means for both Accounting and ICT students. This indicates that HR students were less confident that their degree would ensure employment. There was also a significant interaction between gender and field of study $(F(2,189)=3.60, p<0.02)$. Figure 10 shows this interaction.

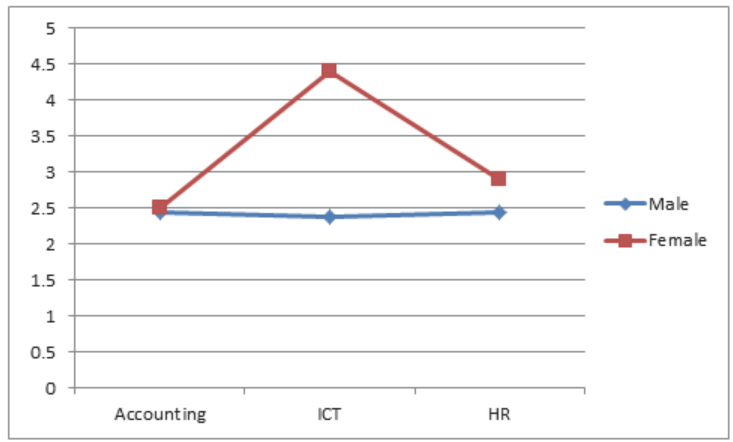

Figure 10: Mean scores for an interaction between gender and field of study indicating students' lack of confidence in their own degree ensuring employment

As shown Figure 10, there were no significant mean differences between male and female students in the Accounting field of study with respect to their levels of confidence. There were however, significant mean differences between male and female students from the ICT and HR fields of study. The mean scores for the female students in both the HR and ICT fields of study were significantly higher than those of the male students. This implies that female students, compared to male students, in both these fields of study were less confident that their degree would ensure employment prospects.

Analysis of the data with regards to students' feelings of hopelessness relating to employment prospects showed no main effect of gender $(F(1,174)=1.01, p>0.05)$ and field of study $(F(2,174)=0.54, p>0.05)$.

\section{Discussion}

\subsection{Employment prospects}

The purpose of this study was to investigate final black male and female final year students' perceptions regarding their employment prospects. The analysis showed that males perceived luck as an important determinate of one's employment. Literature (e.g., Gurney, 1981) supports this finding when he found that the propensity to make external attributions was more for males than females. Males students' perceptions confirm that, to them, the task of finding a job is out of their control, may be because of gender-based affirmative action policies where women are given first preference.

Students studying HR believe that luck plays an important role in determining their employment opportunities compared to ICT and Accounting students. One factor that could have contributed to this perception is the fact that HR is regarded as a 'soft skill' profession and the employment demands for HR specialists are not as high as those of Accounting and ICT (Moleke, 2005). Furham (1984) argues that people who feel prone to unemployment are more likely to attribute the situation to external factors. Thus, HR students, who believe that they possess soft skills compared to the other two fields, are more likely to attribute their employment prospects to external factors such a luck.

Male participants perceived qualifications as determinants of employment more than females. The results contradict literature ( Furham \& Rawles, 1996) who found that females were more likely to qualifications as determinants of employment. Qualifications can be regarded as an internal attribution factor. It is not interesting however, to note that males, who are regarded as second class beneficiaries of the affirmative action, are more likely to endorse an internal factor as a determinant of employment than females.

ICT students in the study perceived that government policies play an important role in determining one's employment compared to Accounting and HR students. ICT is one of the areas regarded as a 'scarce' in South Africa (ASGISA, 2006) and any student who studies it is assured of employment, as a result. In addition the observed 
perceptions could be explained by the student's confidence as a result of their hands on experience by virtue of studying at a UoT where they undergo work integrated learning as part of their curriculum learning.

The mean of HR students was lower than those of ICT and Accounting with respect to the role of individual responsibility in employment prospects. The results suggest that HR students did not agree that it is the job-seeker who determines his/her own employment. Previous findings in this study have also shown that HR students believe that luck determines employment, not the job-seeker. This could possibly be because selection of students with an HR degree is sometimes rigorous, and that few of them are accepted for Masters. These factors might have given the students the perception that employment prospects are entirely not depended on them. ICT students regard individual effort as an important determinant of employment. In many natural science fields, success usually depends on one's achievement. Thus, the higher the marks, the more likely is one to be employed, unlike in the HR field, eve with a distinction, one might find themselves without a job.

Multiple comparison tests showed that male students from ICT endorsed the role of individual effort in getting employed compared to females. The reason could be that male students feel that though they are beneficiaries of affirmative action policies, compared to females especially in the natural sciences fields, their employment would have to be based on high marks. Among HR students, female students endorsed the role of job-seeker in determining employment more than males. The nature of such difference would need further investigation.

\subsection{Job-seeking strategies}

Job-seeking strategies have been reported in literature (Schoer \& Leibbrandt, 2006) as falling into two channels, that is (1) social networks (friends, relatives, groups, etc), (2) formal channels (newspapers, contacting employers, sending emails, etc). Other authors (Furnham \& Rawles (1996) mention registering with employment agencies, seeking party-time employment, internet searches, and volunteering as other job-seeking behaviours. In this study, it is interesting to note that female students were more positive about the importance of using newspapers, taking a job interest test, sending out e-mails and approaching lecturers. Schoer and Liebbrandt (2006) state that costs are a predicate of job seeking behaviours. Therefore, the motivating factors for female students in using these strategies could be the cost of buying newspapers, little or no travelling expenses or internet costs.

The preference in using e-mails shown by the ICT students more that HR and Accounting students is surprising. The reason for the surprise are that at the UoT where the study was conducted, all students, regardless of study field have access to internet and all have university email addresses. The differences could further be explored because they are unlikely to be due to exposure differences of making e-mail enquiries.

Lecturers are sometimes seen as a link between student and prospective employers. They direct students on where to seek employment, in some instances. Results of the current study showed that Accounting students compared to HR and ICT were less likely to seek help from lecturers in for job-related assistance. Among the three fields, HR students were more positive about lecturers' help. The interaction between gender and field of study was found significant. Male and female students in the Accounting filed did not show any difference regarding the importance of approaching lectures for job-related assistance. However, among ICT students, makes compared to females were more likely to indorse the idea of approaching lecturers for job related assistance. Conversely, females compared to males perceived consulting lecturers as being important when seeking employment. The possible reasons for these differences, besides the affirmative action effects could further be explored.

HR students regarded volunteer work as more important in seeking employment than ICT and Accounting students. Graduates from UoTs usually graduate with skills and competences to secure employment because of the work-integrated learning (WIL) component of their curriculum. At the time of study, WIL had not yet been part of HR programme and therefore students from this field might have perceived competition in the labour market among HR graduates in terms of securing employment hence, volunteering (Furnham \& Rawles, 1996) was seen as an option to penetrate the labour market. Additionally, HR students were also less confident that their degree would ensure employment, confirming their ealier perceptions about the need to do volunteer work to seek employment.

Male and female students in Accounting showed no differences in the level confidence of their degree ensuring employment. It is interesting to note that female students compared to males in ICT and HR had higher mean scores, meaning that they were less confident that their degrees would ensure employment. The results are intriguing, since gender-based affirmative action generally benefits females more than males. However, the results confirm previous findings in this study in which females feel that individual effort is more important than external support. What this entails is that, even though the female students are aware that gender-based affirmative action policies are available that 
benefits them, their implementation might not be as expected and therefore employment is not guaranteed. Additionally, findings could be attributed to the students' knowledge of information regarding the high number of unemployed graduates from the HR field in the country.

\section{Contribution of the Study}

This study differs significantly from those done internationally which are outdated. Few done in South Africa focused on other types of universities and not UoTs and included 'race' as a variable in their analysis. The results of the study suggest perceptual gender and field of study differences regarding employment prospects among black male and female students as beneficiaries of affirmative action policy, and studying at a UoT in South Africa.

The study did not take into consideration personality issue which could also be a possible contributory factor in external or internal attributions of employment prospects. Future research could assess students' locus of control and attributions. The study could also have used mixed methods in determining students' perceptions so that the 'why' of perceptions could be further understood. Future research could also be extended to other UoTs so that the differences found are not only unique to where the study was conducted. Other variables like race could also be added in future research, especially among UoTs.

\section{Conclusion}

The study has provided some insights into black male and female (as beneficiaries of the affirmative action policy) final year students' perceptions of employment prospects at a UoT in South Africa, especially with respect to the role of internal and external factors in determining such prospects. Important gender and field of study differences were unearthed. These are fundamental issues to consider, especially in South Africa when trying to understand, not only final year student's perception of future employment, but also graduates' job-seeking behaviours.

\section{References}

Accelerated and Shared Growth Initiative for South Africa (2006). A catalyst for accelerated and shared growth-South Africa. [Online] Available: http://www.commerce.uct.ac.za/research_units/dpru/DPRUConference 2006/Papers. (August 13, 2008).

Altbeker, A., \& Storme, E. (2013). Graduate unemployment in South Africa; A much exaggerated problem. South Africa: The Centre for Development and Enterprise,Johannesburg.

Chandra, V., Moorty, L., Rajaratnam, B. \& Schaefer, K. (2001). Constraints to Growth and Employment in South Africa. Report No. 1: Statistics from the Large Manufacturing Firm Survey, Informal Discussion Papers on Aspects of the Economy of South Africa, No. 14.

Development Policy Research Unit (2006). Graduate Unemployment in Post-Apartheid South Africa: Nature and Possible Policy Responses. Research report compiled for business leadership South Africa. [Online] Available: http://www.tips.org.za/events /forum2006/papers/KPauw Graduate Unemployment.pdf. (August 10, 2008).

Furnham, A. (2002). Explanations for unemployment in Britain. European Journal of social psychology, 12, 335-352.

Furnham, A., \& Rawles, R. (1996). Job search strategies, Attitudes to school and attitudes about employment. Journal of Adolescence, 19, 354-369.

Goldsmith, A. H. \& Venum, J. R. (2000). The Psychological Impact of Unemployment and Joblessness. Journal of Socio Economics, 25 , 333-355.

Goodwin, C.J. (2002) Research in Psychology: Methods and Design. New York: John Wiley.

Gray, D.E. (2006). Doing Research in the Real World. London: Sage Publications Ltd.

Gurney, R. (1981). Leaving school, facing unemployment and making attributions about the causes of unemployment. Journal of Vocational Behaviour, 18, 79-91.

Kingdon, G.G. \& Knight, J. (2000). Unemployment in South Africa: The Nature of the Beast. Paper presented at the Trade and Industrial Policy Strategies Annual Forum, Muldersbush.

Koen, C. (2003). The contribution of technikons to human resource development in South Africa. DPRU Working paper No. $03 / 80$. Development policy research institute, University of Cape Town.

Kraak, A. (2003). HRD and the Skills Crisis. In A. Kraak, \& H. Perold (Eds.), Human Resources Development. Education, Employment and Skills in South Africa. Pretoria: HSRC Press.

Kraak, A. (2005). An overview of South African Human Resources Development. Cape Town: HSRC Press.

Lawless, A. (2006). Number and Needs. A wake Up Call to address the capacity crisis in SA Civil Engineering. South African Institution of Civil Engineering [Online] Available: http:// www.civils.org.za. (August 10, 2007).

Madi, P. M. (1997). Black Economic Empowerment in the new South Africa: The rights and the wrongs. Randburg: Knowledge Resources. 
Mlatsheni, C. (2005). The youth labour market: What does it take to succeed? Mimeo.

Moleke, P. (2005). Finding Work: Employment Experiences of South African Graduates. Compiled by the Employment and Economic Policy Research Programme. Pretoria: HSRC Press.

Nel, E. L. (2011). The Justifications and Limits of Affirmative Action: A Jurisprudential and Legal Critique. Unpublished Dissertation: Stellenbosch University; Cape Town.

Papier, J. (2006). FET Seminar: Youth Unemployment and Education in South Africa. Paper presented at the Harold Wolpe Memorial Trust and Inset Providers Coalition (IPC) 49th Open Dialogue Event., 2 February 2006, Cape Town.

Pauw, K. \& Edwards, L. (2005). Evaluating the General Equilibrium Effects of a Wage Subsidy Scheme for South Africa. Paper presented at the Biennial Conference of the Economic Society of South Africa, 17 - 19 September 2003, Somerset West.

Pauw, K., Oosthuizen, M. \& Van der Westhuizen, C. (2006). Graduate Unemployment in the face of skills shortage: A labour marker paradox. South African Journal of economics, 76(1), 45-57.

Robinson, V., Gedye, L., Mabanga, T., \& Tabane, R. (2005). Shortage Confusion Mismatch Surplus. Mail \& Guardian, 2 August 2005.

Schomburg, H., \& and Teichler, U. (2000). Higher Education and Graduate Employment in Europe:

Results from Graduate. USA: Springler

Singer, M. S., Stacey, B. G. and Ritchie, G. (1987). Causal Attributions for Unemployment,

Perceived Consequences of Unemployment, and Perceptions of Employment Prospects for Youth among University Students in New Zealand. Journal of Genetic psychology: Research and Theory on Human Development, 148(4), 507-517.

Tomu, H. (2013). Perceptions Regarding Employment Prospects among Final Year Students as

Determined by Field of Study, Gender and Race. International Journal of Academic Research in Business and Social Sciences 3(1) 2222-6990.

Turner, M.E. \& Pratkanis, A.R. (1994). Affirmative Action: Insights from Social Psychology and Organisational Research. Basic and Applied Psychology, (15), 1-11.

Winefield, A.H., Winefield, H. R., Tiggemann, M. and Goldney, R. D (1991)._A longitudinal study of the psychological effects of unemployment and unsatisfactory employment on young adults. Journal of Applied Psychology, 76(3), 424-431. 